\title{
Reducing Buyer Search Costs: Implications for Electronic Marketplaces
}

\author{
J. Yannis Bakos \\ Stern School of Business, New York University \\ 44 West $4^{\text {th }}$ St, New York, NY 10012 \\ (email: bakos@stern.nyu.edu; web: http://www.stern.nyu.edu/ bakos)
}

Management Science, Vol. 43, No. 12, December 1997

\begin{abstract}
Information systems can serve as intermediaries between the buyers and the sellers in a market, creating an "electronic marketplace" that lowers the buyers' cost to acquire information about seller prices and product offerings. As a result, electronic marketplaces reduce the inefficiencies caused by buyer search costs, in the process reducing the ability of sellers to extract monopolistic profits while increasing the ability of markets to optimally allocate productive resources. This article models the role of buyer search costs in markets with differentiated product offerings. The impact of reducing these search costs is analyzed in the context of an electronic marketplace, and the allocational efficiencies such a reduction can bring to a differentiated market are formalized. The resulting implications for the incentives of buyers, sellers and independent intermediaries to invest in electronic marketplaces are explored. Finally, the possibility to separate price information from product attribute information is introduced, and the implications of designing markets promoting competition along each of these dimensions are discussed.
\end{abstract}

Copyright (C) 1997 by The Institute of Management Sciences

Keywords:

electronic markets, search costs, consumer search, electronic commerce, Internet markets 


\section{Introduction}

The 1990s have seen an explosive growth of networks and information systems that cross organizational boundaries. These systems often can bring together buyers and sellers in a market, as has been the case, for example, with airline reservation systems. The result is an electronic market system, or electronic marketplace (e.g., Bakos 1987, Malone et al 1987). The strategic potential of these systems has been demonstrated in several industries (e.g., see Bakos 1991 for a general discussion and Hopper 1990 for a discussion of the impact on a specific industry). The importance of electronic marketplaces is dramatically increasing, however, as interorganizational networking becomes widely available through high speed digital telecommunications services and the Internet, encompassing hundreds of thousands of businesses and millions of individual consumers. This trend is further amplified as the cost of participating in an electronic marketplace is lowered by emerging public and private standards for access and information exchange over the Internet, such as the hypertext markup language (HTTP) protocols, the secure sockets layer (SSL) architecture for secure information exchange, and CommerceNet's (www.commerce.net) suite of standards for electronic commerce.

In the context of this article, an electronic marketplace or electronic market system is an interorganizational information system that allows the participating buyers and sellers in some market to exchange information about prices and product offerings. We focus on the role of these electronic marketplaces in bringing together buyers and sellers in settings such as airline reservation systems, Internet-based electronic storefronts, or financial markets. We are not concerned with transaction-oriented benefits realized after a bilateral relationship has been established, ${ }^{1}$ or with electronic data interchange (EDI) or electronic payment systems which are primarily transaction-oriented. Furthermore, while electronic marketplaces affect several other parameters of commerce, such as security, privacy, settlement, etc., this paper focuses on the impact of lower search costs. This definition of electronic marketplaces is substantially narrower than the view of "electronic markets" as information-technology based governance mechanisms (e.g., Malone et al 1987), or as coordination mechanisms (Malone and Crowston 1994). Specifically, this article studies the market-making functionality of electronic marketplaces during the processes of price discovery and identification of appropriate product offerings in a market.

1 For instance, real-world systems often offer such benefits beyond their market-related functionality, e.g., airline reservation systems offer billing, itinerary and ticket printing functions and financial market systems may support transaction settlement; however these features are separable from the market intermediation process, and their value is added after the matching of a buyer and a seller has taken place. 
The article is organized as follows: Section 2 briefly reviews commodity markets, where electronic marketplaces can promote price competition among sellers by increasing the availability of price information; in this scenario, moving a market "on-line" can have a dramatic impact on seller profits and buyer surplus. Most markets, however, are characterized by heterogeneous consumer tastes and a variety of product offerings. The role of electronic marketplaces in these markets is more complex, as buyers need to obtain information about product characteristics as well as prices.

Section 3 analyzes the role of search costs in a market with heterogeneous product offerings and consumer tastes by introducing search costs in a spatially differentiated market. In this setting, buyer search costs can result in substantial allocational inefficiencies and sellers can exploit these search costs to extract monopolistic rents. It is shown that reducing the cost of price and product information typically will improve market efficiency but will reduce seller profits. By reducing search costs, electronic marketplaces may enable the emergence of new markets or prevent the breakdown of existing ones.

Section 4 addresses the impact of electronic marketplaces on the investment incentives of buyers and sellers, which may lead to underinvestment by sellers and overinvestment by buyers. Section 5 introduces the possibility to separate buyer search costs into their component costs of searching for price information and searching for product information, and explores the implications for the design and impacts of electronic marketplaces. Finally, Section 6 discusses some implications of electronic marketplaces for the structure and efficiency of market-mediated transactions and outlines and agenda for further research.

\section{Electronic Marketplaces and Search in Commodity Markets}

In commodity markets, all sellers are assumed to offer identical products; thus the role of an electronic marketplace is to provide information about the existence and the price of a seller. There is a well developed literature on buyer search in commodity markets, with Diamond (1985) and Stiglitz (1989) providing excellent reviews. Introducing a search $\operatorname{cost}^{2}$ in the traditional models of commodity markets can result in monopolistic pricing by the sellers ${ }^{3}$. Thus even modest search costs can lead to prices substantially higher than marginal costs, even when sellers do not behave collusively in commodity markets.

2 In this article we adopt the standard definition of buyer search cost in the economic literature as the cost incurred by the buyer to locate an appropriate seller and purchase a product. This would include the opportunity cost of time spent searching as well as associated expenditures such as driving, telephone calls, computer fees, magazine subscriptions, etc.

3 This is a standard result in most search models in the literature, as noted by Diamond (1985) and Stiglitz (1989). 
Electronic marketplaces providing price information will reduce the incremental cost of obtaining information about additional sellers and they may also reduce the ability of sellers to obscure their quoted prices (e.g., by including or excluding transportation costs, incentives, special promotions, financing costs, etc.) In that respect, electronic marketplaces are likely to move commodity markets closer to the classical ideal of a Walrasian auctioneer where buyers are costlessly and fully informed about seller prices. Since the assumption of fully informed buyers leads to the competitive price-taking equilibrium in the classical market model, and it underlies results such as Bertrand's zero-profit equilibrium in oligopolistic settings, we expect that electronic marketplaces typically will sway equilibria in commodity markets to favor the buyers, will promote price competition among sellers, and will reduce sellers' market power.

If electronic marketplaces lead to a large enough reduction in search costs, they may destabilize profitable oligopolistic pricing in a commodity market and instigate price wars that wipe out any excess profits enjoyed by the sellers. This is not surprising, as a commodity product bought from different sellers can differ only in its price. As electronic marketplaces make the distribution of information more efficient, the opportunities for fat and easy profits will shrink. Sellers may attempt to delay the arrival of such systems, or may try to control them. For example, at the Eurobond market's 1987 annual meeting in Oslo, Salomon Brothers led the major American trading firms in successfully opposing proposals for a computerized price-quotation system for the trading of Eurobonds (Economist 1987). Such a system would make market information available instantly to all subscribing investors and traders, regardless of their size or location, and could mark the end of big trading profits as bonds of similar credit rating, interest rate and maturity are virtually interchangeable commodities. Indeed, dealers were able to resist and delay the introduction of such systems into the mid-1990s, even in the face of pressure from government regulators.

\section{Electronic Marketplaces and Search in Differentiated Markets}

Although certain markets involve commodity products, like government bonds or most agricultural and mineral products, most markets are characterized by differentiated products. The prevalence of differentiated markets is a result of the heterogeneity of buyer preferences and the profit opportunities these markets offer to sellers. Differentiated markets involve a variety of product offerings and consequently the search problem buyers face in these markets becomes complicated by the need to consider both the price of a particular seller and the characteristics of the corresponding product offering.

Electronic marketplaces in differentiated markets will therefore need to provide both price and product information, to enable the comparison of different product offerings. While 
price information is relatively easy to convey, providing adequate product information poses a challenge that system designers have been trying to address since the early days of such systems. For example, a central feature of both the American Gem system, used for the trading of precious stones, and the AucNet system, used for the trading of used cars, was the provision of a standardized rating system for the quality of the items featured on the system's electronic market (HBS Case Studies 1988, 1989). The increasing multi-media capabilities in the Internet, which now allows the transmission of high resolution images, video and three-dimensional virtual environments, create unprecedented opportunities for the design of electronic marketplaces that effectively convey product information at reasonable cost.

Economists have been interested in differentiated markets since the late 1920's, and have proposed two major types of models for their study: spatial differentiation models tracing their origin to Hotelling's (1929) formalization of spatial competition, and brand substitution models whose origin is often attributed to Chamberlin (1933). In spatial differentiation models, like the one developed in this section, brand attributes are treated as choices of location in a multi-dimensional space. A consumer's preferences determine the location of her ideal product or product mix, and some type of distance metric in the product attribute space is used as a proxy for the utility loss, or "fit" cost, when a consumer is not able to purchase her ideal brand or a perfectly substituting mix of brands. These models highlight the importance of brand attributes (product offerings) and the dynamic aspects of competition through the reformulation of existing brands or through the introduction of new ones (Schmalensee 1978, Perloff and Salop 1985).

\subsection{A Model of Search Costs in Differentiated Markets}

Diamond (1985) notes that "search theory and empirical work have a long way to go until we have satisfactory answers to a number of allocation questions that are totally ignored in a Walrasian setting. ... Nothing has been done to marry the underlying search issues with some of the realities of the geographic distributions of consumers and firms and ... very little has been done to model the search basis for the role of intermediaries." This section addresses these issues by introducing search costs to a "unit circle" or "city around the lake" setting, similar to Salop's (1979) model of spatial differentiation.

Specifically, in a world with differentiated product offerings along a unit circle, as shown in Figure 1, a buyer is required to pay a search cost to find the location (i.e., the product characteristics) and the price offered by some seller, and then decides whether to purchase 


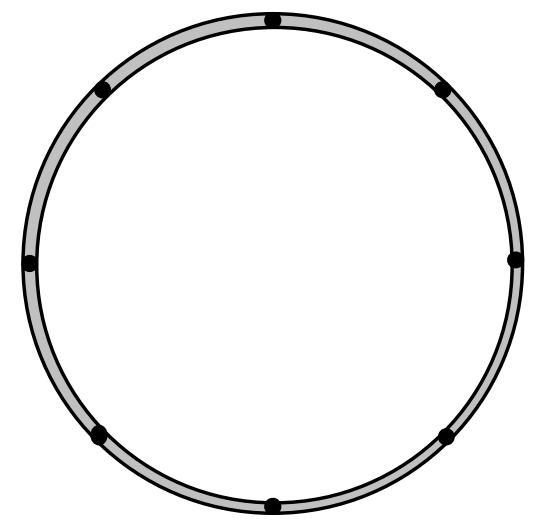

- $m$ sellers

- $n$ buyers

Figure 1: A model with product differentiation

one of the products already identified or to keep searching. ${ }^{4}$ The distance between a buyer's ideal product and the location of an actual product offering imposes on the buyer a "fit" cost, which represents the loss of utility from obtaining a less than ideal product. We find that in this type of setting, an electronic marketplace providing buyers with low-cost product and price information can generate substantial allocational efficiencies by enabling these buyers to locate sellers that better match their needs. ${ }^{5}$

\section{Model 1}

Consider a market with $n$ buyers and $m$ sellers for a good that is spatially differentiated along a single dimension, represented by a unit circle. Buyer tastes are heterogeneous and uniformly distributed along this unit circle, and seller offerings are differentiated along the same dimension. If buyers purchase a good that does not perfectly match their taste, they incur a "fit" cost $t$ per unit of distance between their location on the circle and the location of the seller offering they purchase; this cost represents their utility loss for acquiring a good different from their ideal one. All buyers have identical unit demand in each period, subject to a reservation utility $r$. They are risk neutral, and they will enter the market if they expect the total cost of their purchase to be less than or equal to $r$. Sellers are risk neutral as well,

4 The choice of a unit circle setting simplifies the analysis but does not substantially affect the resulting equilibria; similar results will be obtained in linear models like Hotelling's.

5 It should be noted that this analysis is entirely different from interpreting the transportation cost in Salop's (1979) and other similar models as a "search" cost, like the cost of visiting a seller known to carry a desirable product. Such an interpretation would force the "search" cost to be the only differentiating characteristic of different products, reducing the setting to a commodity market with search costs. The model developed in this section allows products to be differentiated independently from the cost of obtaining information about their characteristics, which is essential in studying the role of an electronic marketplace in a differentiated market. 
and they each supply a single good for which they face a constant marginal cost (assumed for convenience to be zero).

Sellers move first by deciding where to locate their product offerings and how to set their prices. All sellers seem ex ante identical to buyers, as buyers have no prior knowledge of the location along the unit circle or the price of seller offerings. ${ }^{6}$ Each buyer can learn the price and location of the product offering of an additional seller (up to the $m$-th seller) by paying a constant search $\operatorname{cost} c$. At this point the buyer must decide whether to purchase from one of the sellers whose product/price characteristics have been discovered, or to "invest" in information about an additional seller by incurring the corresponding search $\operatorname{cost} c$. This defines the buyers' strategy space. To simplify the analysis, we assume that buyers sample the sellers with replacement, which means that buyer priors do not change after each additional inquiry. ${ }^{7}$ The number of sellers $m$ is common knowledge, resulting in buyer priors that there is a seller with probability $m \cdot d x$ along any differential segment of the unit circle with length $d x$; let $f$ denote the buyers' prior distribution for seller prices. Finally, sellers cannot observe the location of visiting buyers, and thus cannot price discriminate.

In this setting, we explore the existence of Perfect Bayesian Equilibria, i.e., perfect equilibria that satisfy the rational expectations constraint that $f$ is the actual distribution of seller prices. ${ }^{8}$ Analyzing a single period setting also means that we ignore the effects of reputation.

Although this may be unduly restrictive in certain economic relationships characterized by repeated interactions between the same agents, it is typical for models in search theory ${ }^{9}$ because it simplifies the analysis by restricting attention to equilibria in the one-period stage

6 This assumption implies that as the number of sellers increases, it becomes commensurately less likely to land on any specific seller, which may not hold if buyers can "direct" their search toward (or away from) certain product characteristics. The implication seems in line, however, with the experience of trying to locate sellers on the Internet, where search engines like Alta-Vista return long lists of potentially relevant sites.

7 This assumption does not significantly affect buyer behavior as long as the number of inquiries at equilibrium is much smaller than $m$. It also does not affect seller behavior as sellers cannot adjust their price and product offering in response to buyer search histories. In the case where buyers adjust their priors after each inquiry, the qualitative nature of the results does not change, and our model marginally underestimates buyer welfare in the resulting equilibrium (also see footnote 14).

8 This setting could be thought of as the stage game for a repeated game. Since there is no state variable to affect play in subsequent periods, the equilibria derived for the one-period game trivially extend to Markov perfect equilibria for the multi-period game, i.e., equilibria that depend only on particular states of the market and not on past history.

9 Diamond (1985) notes that "all the models [reviewed] omit or severely limit ... price reputations. This is a major hole in the existing literature. Significant progress in this area will probably have to await the discrimination of cases in which optimal strategies are ... stationary, from those in which optimal strategies involve building up a reputation which is then run down." While studying the role of reputation in noncooperative situations is a very complex undertaking (e.g., see Fudenberg 1991) and would distract from the thrust of this article, reputation issues as they relate to market participants and intermediaries are clearly important and present an interesting area for future research. 
game. The assumptions of constant search costs and inelastic buyer demand are not crucial, and the analysis still holds for increasing marginal cost of search and for elastic but identical buyer demand functions.

If the cost of search is zero, this setting is similar to the one analyzed by Salop (1979), and, as shown there, the unique equilibrium requires all sellers to charge a price $p^{*}=t / 2 m$. In the presence of search costs, however, the equilibrium dynamics change. Interestingly, for a large enough number of sellers, $m$, the equilibrium price does not depend on $m$, while it depends on both the degree of differentiation $t$ and the search $\operatorname{cost} c$.

\section{Equilibria}

A buyer with prior $f$ for the distribution of seller prices, and who has already located a most desirable offering at price $S$ and distance $D$ along the unit circle, which we denote with the pair $(S, D)$, will only buy from sellers in the interval $[-D-S / t, D+S / t]$ relative to that buyer's location. ${ }^{10}$ If a seller in that interval located at distance $x$ offers price $p$, the buyer faces a price of $p+x t$ (adjusted for "fit"), and will be willing to purchase if $p+x t<S+D t$. Thus, a buyer's expected gain from searching for one more seller is given by

$$
\begin{aligned}
& g(S, D)=2 \int_{x=0}^{D+S / t} \int_{p=0}^{S+D t-x t}(S+D t-x t-p) f(p) d p d x, \text { which can be written as } \\
& g(S, D)=2 \int_{x=0}^{D+S / t} \int_{p=0}^{S+D t-x t} F(p) d p d x
\end{aligned}
$$

As $g(S, D)$ is strictly increasing in $S+D t$, at any Perfect Bayesian Equilibrium buyers will keep searching if and only if $g(S, D)>c$, i.e., they will set a reservation price $R=R(c, t, f)$ for $S+D t$, and keep searching if $S+D t>R$. This reservation price is identical for all buyers by symmetry, and its value does not change as searches do not change buyers' priors.

Since buyers adopt reservation price strategies, any seller that raises its price will price out marginal buyers increasingly closer to that seller's location on the circle. As a result, each seller faces a downward sloping demand curve and a strictly decreasing marginal revenue curve, which results in a unique price $p^{*}$ for that seller that maximizes its expected profits. Consequently sellers will only adopt pure strategies at equilibrium: any mixed strategy that requires a seller to charge a price $p \neq p^{*}$ with positive probability is dominated, since the

10 This is because a seller outside that interval could not attract the buyer even with a price of zero.

11 The result for the inner integral is derived as follows, with $R=S+D t-x t$ and using integration by parts: $\int_{0}^{R}(R-p) f(p) d p=\int_{0}^{R}(R-p) \frac{d F(p)}{d p} d p=\int_{p=0}^{p=R}(R-p) d F(p)=[(R-p) F(p)]_{p=0}^{p=R}+\int_{0}^{R} F(p) d p=\int_{0}^{R} F(p) d p$ 
seller could increase its profits by discontinuing price $p$ and correspondingly increasing the probability of charging $p^{*}{ }^{12}$ Furthermore, seller prices will be symmetric: the principle of maximum differentiation applies as in Salop (1979), requiring all sellers to position themselves symmetrically around the unit circle and charge an identical price $p^{*} .{ }^{13}$

To determine the price charged, consider such an equilibrium with $p=p^{*}$ for all sellers, i.e., $F(p)=0$ for $p<p^{*}$ and $F(p)=1$ for $p \geq p^{*}$. Then Equation (1) implies that $g(S, D)=2 \int_{x=0}^{D+S / t}\left(S+D t-p^{*}-x t\right) d x$, where the integrand cannot assume negative values, i.e., $x \leq D+\left(S-p^{*}\right) / t$. Thus $g(S, D)=2 \int_{x=0}^{D+\frac{S-p^{*}}{t}}\left(S+D t-p^{*}-x t\right) d x=\frac{1}{t}\left(S+D t-p^{*}\right)^{2}$ and solving $g(S, D)=c$ gives $\frac{1}{t}\left(S+D t-p^{*}\right)^{2}=c$, i.e.,

$$
\therefore \quad S+D t=p^{*}+\sqrt{c t}
$$

According to equation (2) each seller receives sales from an interval $[-\sqrt{c / t}, \sqrt{c / t}]$ around that seller's position. That interval is of length $2 \sqrt{c / t}$, and we refer to it as that seller's territory. Similarly, each buyer is willing to buy from sellers in an interval $[-\sqrt{c / t}, \sqrt{c / t}]$ around that buyer's position, which we refer to as that buyer's neighborhood. ${ }^{14}$ If seller territories and buyer neighborhoods are of length $l$, then a given seller gets the business of those of the $\ln$ buyers in its territory who visit that seller before they visit any of the other $\operatorname{lm}$ sellers in their neighborhood, and thus on expectation sells to $n / m$ buyers.

12 Sellers would never resort to mixed strategies in order to affect buyers' reservation prices, either; higher variance in seller prices can only lower buyers' reservation price.

13 If sellers cannot observe other seller offerings before choosing their spatial location, they will still be uniformly distributed on expectation. If they can observe other seller offerings after choosing their location but before choosing their price, the resulting equilibrium will not be symmetric, with higher prices in thinly populated (less competitive) areas on the circle. However, the impact of search costs remains qualitatively similar to our analysis and the two models converge as the number of sellers increases.

14 In the case of search without replacement, buyers will adjust their priors after each inquiry, increasing the probability that a desirable seller offering will be discovered in the next search, given that a number of unacceptable ones have been located so far. Specifically, on the $k$-th search the equilibrium condition in equation (2) becomes $\frac{m-1}{m-k} \frac{1}{t}\left(S+D t+p^{*}\right)=c$, leading to decreasing reservation prices $R_{k}=p^{*}+\sqrt{\frac{m-k}{m-1} c t}$, and correspondingly shrinking buyer neighborhoods. The impact of changes in search costs on the equilibrium outcomes will be qualitatively similar, and if $m$ is large enough so that $(m-1) /(m-k)$ stays close enough to 1 , the models will converge. 
At equilibrium, any seller $i$ is maximizing profits taking other sellers' price as given, and thus has no incentive to deviate unilaterally by charging a different price, i.e.,

$$
\frac{d}{d p_{i}}\left[p_{i} Q_{i}\left(p_{i}, p_{j \neq i}^{*}\right)\right]_{p_{i}=p^{*}}=0
$$

where $Q_{i}\left(p_{i}, p_{j \neq i}^{*}\right)$ denotes the sales of seller $i$ when the price charged by $i$ is $p_{i}$ while every other seller $j \neq i$ charges price $p^{*}$. Thus

$$
Q_{i}\left(p_{i}^{*}, p_{j \neq i}^{*}\right)+p^{*} \frac{d}{d p_{i}}\left[Q_{i}\left(p_{i}, p_{j \neq i}^{*}\right)\right]_{p_{i}=p^{*}}=0
$$

A deviation by seller $i$ of $d p_{i}=-\delta$, i.e., charging a discount price of $p^{*}-\delta$, results in an increase of $2 \delta / t$ in $i$ 's territory, and new sales of

$$
\frac{2 \sqrt{\frac{c}{t}}+2 \frac{\delta}{t}}{2 \sqrt{\frac{c}{t}}} \frac{n}{m}=\left(1+\frac{\delta / t}{\sqrt{c / t}}\right) \frac{n}{m} .
$$

Thus:

$$
\begin{gathered}
d Q_{i}\left(p_{i}^{*}, p_{j \neq i}^{*}\right)=\frac{\delta / t}{\sqrt{c / t}} \frac{n}{m}=-\frac{d p_{i} / t}{\sqrt{c / t}} \frac{n}{m} \\
\therefore \quad \frac{d}{d p_{i}}\left[Q_{i}\left(p_{i}^{*}, p_{j \neq i}^{*}\right)\right]=-\frac{1}{\sqrt{c t}} \frac{n}{m}
\end{gathered}
$$

Since $Q_{i}\left(p_{i}^{*}, p_{j \neq i}^{*}\right)=n / m$, it follows from equations (3) and (4) that:

$$
\begin{gathered}
\frac{n}{m}-p^{*} \frac{1}{\sqrt{c t}} \frac{n}{m}=0 \\
\therefore \quad p^{*}=\sqrt{c t}
\end{gathered}
$$

Thus at the unique symmetric equilibrium each seller charges price $p^{*}=\sqrt{c t}$ and buyers' reservation price is $R=p^{*}+\sqrt{c t}=2 \sqrt{c t}$. Each buyer searches until a seller within distance $\sqrt{c / t}$ is located, i.e., their neighborhood is of length $2 \sqrt{c / t}$. Each search is a Bernoulli trial with success probability $2 \sqrt{c / t}$, and an acceptable seller will be located after $\frac{1}{2}(c / t)^{-\frac{1}{2}}$ trials 
on the average, incurring expected search costs of $\frac{1}{2} c(c / t)^{-\frac{1}{2}}=\frac{1}{2} \sqrt{c t}$. The best seller located will be on the average at a distance of $\frac{1}{2} \sqrt{c / t}$, resulting in an expected fit cost of $\frac{1}{2} t \sqrt{c / t}=$ $\frac{1}{2} \sqrt{c t}$. Given that the buyer pays a price of $\sqrt{c t}$, the buyer's expected utility is $r-2 \sqrt{c t}$.

If the number of sellers is large, in the absence of search costs each buyer will be matched to its ideal seller and the Bertrand-like equilibrium is characterized by zero seller profits and correspondingly low allocational inefficiencies ("fit" costs). When search costs are introduced, each buyer incurs a loss of $\sqrt{c t}$ because of search costs and the disutility of purchasing a less-than-ideal product offering (the "fit" cost), resulting in a total inefficiency of $n \sqrt{c t}$.

\subsection{Electronic Marketplaces Can Prevent Market Failure}

The above discussion assumes that $r \geq 2 \sqrt{c t}$, i.e., buyers' reservation utility is high enough so that no buyers are priced out of the market. If $2 \sqrt{c t}>r \geq \sqrt{c t}$, then sellers find that their sales (and profits) disappear when they charge a price above $r-\sqrt{c t}$, and the unique equilibrium requires sellers to charge price $p^{*}=r-\sqrt{c t}$. Finally if $r<\sqrt{c t}$, buyers will stay out of the market even if they are offered a zero price; they would find it too costly on expectation to locate an acceptable seller, even though for a large enough number of sellers such a seller is guaranteed to exist. Thus, high search costs can lead to a market breakdown. This result illustrates the importance of search costs and the difference of our setting from similar settings with free information; in Salop's (1979) model, for example, sellers will always service their local markets, even if some consumers are priced out because of high transportation costs. Figure 2 shows the impact of increasing search costs on seller prices. By reducing search costs, electronic marketplaces can prevent this type of market breakdown. Similarly, they may enable the creation of new markets that were not previously possible because of high search costs.

The result of market breakdown holds for markets with few sellers as well, where model 1's assumption of sampling with replacement could be unrealistic. To illustrate this, consider a setting similar to model 1 , with a large number $n$ of buyers but with only two sellers, located at diametrically opposed positions (see Figure 3). If buyers sample without replacement, they can anticipate the result of their second search, since they can deduce the prices and product offerings of both sellers from their knowledge of the corresponding probability distributions. Assuming no collusion between the sellers and that no buyers are priced out of the market, all buyers would search at least once. If the search produces a product offering at a distance $x$ 


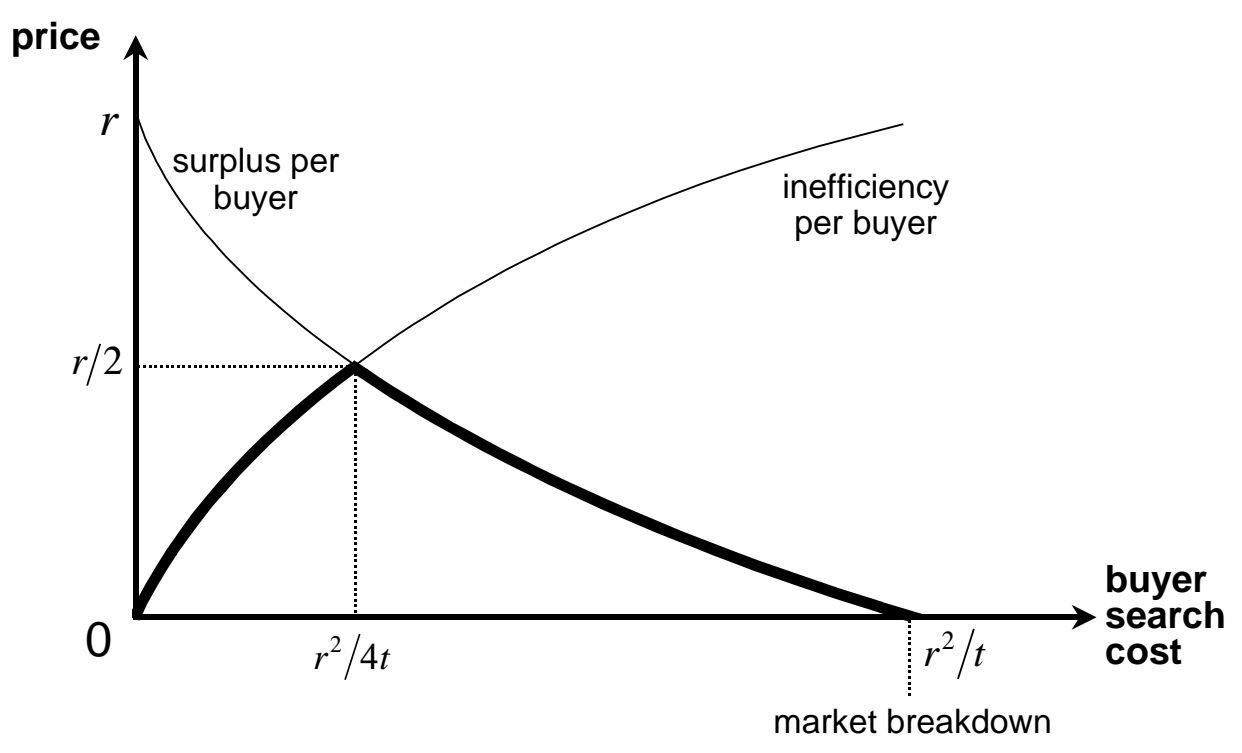

Figure 2: The impact of increasing buyer search costs

higher than $\frac{1}{4}+\frac{c}{2 t}$, buyers will search once again to locate a product at a distance $\frac{1}{2}-x$, which is less than $\frac{1}{4}-\frac{c}{2 t}$, and thus is worth the additional search cost $c$. Buyers at a distance less than $\frac{1}{4}-\frac{c}{2 t}$ from their nearest seller will search either once or twice (until they locate their nearest seller), with an expected search cost of $1.5 c$. The remaining buyers will search only once, at a cost $c$. At equilibrium each seller sells to $n / 2$ buyers, and discounting by $\delta$ increases individual sales by $2 n \delta / t$; the equilibrium price $p^{*}$ must therefore satisfy $\frac{n}{2} \delta=\left(p^{*}-\delta\right) \frac{2 n \delta}{t}$ in the limit as $\delta \rightarrow 0$, and thus $p^{*}=t / 4$.

If the sellers charge a price $p$, a buyer's expected utility (inclusive of search and fit costs) by entering the market is $r-p-c-2 \int_{x=0}^{\frac{1}{4}+\frac{c}{2 t}} x t d x-2 \int_{x=0}^{\frac{1}{4}-\frac{c}{2 t}}(x t+c) d x$. The first three terms take account of the buyer's reservation price, price paid and cost of the first search; the first integration accounts for the expected cost of fit if the buyer purchases from the first seller discovered, and the second integration accounts for the expected cost of fit if a second search is necessary, including the additional search cost. Calculating the above expression gives us an expected utility of $r-p-\frac{3 c}{2}-\frac{t}{8}+\frac{c^{2}}{2 t}$ (provided that $c<\frac{t}{2}$ ). If $c>\frac{t}{2}$, then buyers will search only once, incurring an expected fit cost of $\frac{t}{4}$ : the second search would be too 


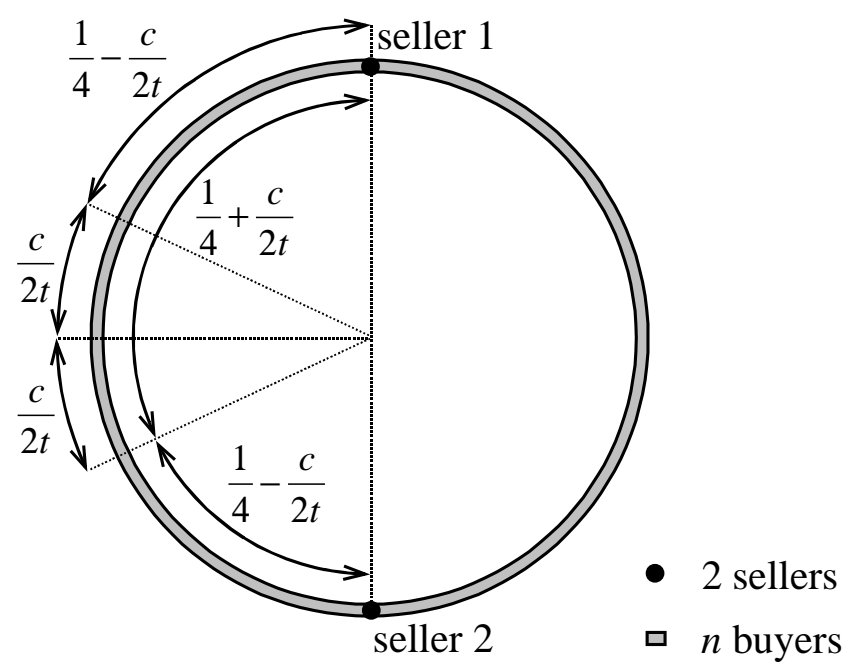

Figure 3: A differentiated market with two sellers

expensive even if it would produce a seller with perfect fit. It follows that buyers will participate in the market if

$$
\begin{array}{ll}
p \leq r-\frac{3 c}{2}-\frac{t}{8}+\frac{c^{2}}{2 t} & \text { if } c \leq \frac{t}{2} \\
p \leq r-c-\frac{t}{4} & \text { if } \mathrm{c}>\frac{t}{2}
\end{array}
$$

It can be seen from Equation (6) that even in a market with only two sellers where buyers search without replacement, large search costs will cause a market breakdown. This is the case even if buyers with preferences close to the seller offerings could have been profitably serviced net of search costs.

This propensity of differentiated markets to break down when search costs are high opens the possibility that electronic marketplaces will enable "missing" markets, thereby creating substantial social surplus. For example, unemployment might be partially explained as a market failure caused by the cost of obtaining information about available "product offerings" (job opportunities) offered by "sellers" (potential employers). At any given time, certain workers are in the process of searching for an appropriate job. Other workers face high search costs relative to their reservation price, and thus stay out of the job market because their participation is unprofitable on expectation. Finally, other workers may be misinformed about the available job opportunities, having unrealistic expectations and setting a high threshold for their search, corresponding to a small "neighborhood" in model 1). Such misinformed workers will take too long to find jobs, and will thus increase the observed level of unemployment. 
An electronic marketplace matching skills with positions could reduce the above three components of unemployment, by reducing the cost faced by workers exploring job openings (including the time of each search). It could also result in a more efficient matching of worker skills to job openings. Indeed, as the Internet reduces the cost of setting up electronic marketplaces in the job market, electronic job listings have grown from only about 15,000 in 1994 to half a million in mid-1996 (Markels 1996), with at least 10 major on-line job banks emerging. There is anecdotal evidence that by reducing search costs, these systems both decrease the time spent searching and allow job seekers to find jobs they would not have searched for otherwise. ${ }^{15}$ A reduction in unemployment even by a small fraction as a result of electronic marketplaces in the labor markets could offer large economic benefits.

\subsection{Electronic Marketplaces Benefit Buyers}

Model 1 shows how buyer search costs allow sellers offering differentiated products to heterogeneous buyers to extract monopolistic rents. This analysis provides formal support for the proposition that electronic marketplaces promote price competition and reduce the market power of sellers, as has been argued by several authors (e.g., Bakos 1991, Clemons 1991, Malone et al. 1987). As electronic marketplaces reduce the search costs of buyers to obtain price and product information, they result in decreased price premiums and seller profit margins.

The optimal strategy for a buyer in a market with search costs is to determine a "price and fit" threshold, and keep searching until a satisfactory product is located. Customers with access to electronic marketplaces, and thus facing lower search costs, become more demanding and are willing to make fewer compromises concerning their ideal product. If the cost of search is low enough, buyers look at all product offerings and purchase the one best serving their needs, resulting in a socially optimal allocation. Buyers are made better off from such a system in three ways: first, they enjoy lower prices because of the increased competition among sellers; second, and equally important, they enjoy allocational efficiencies from being better informed about the available products, thus making better purchasing decisions; finally, they incur lower total search costs, even though they increase their number of inquiries. While lower prices come at the expense of seller profits, better allocation and reduced search costs increase the net social surplus. High search costs, on the other hand, not only lead to efficiency losses, but may cause a market to break down, or may prevent it to arise in the first place.

15 For example, according to a testimonial in (Markels 1996), "The Internet absolutely decreased the time I spent on unemployment. ... Suddenly I had access to jobs all over the country, ... I would never have gotten out of California without it." 


\section{Investment Incentives for Electronic Marketplaces}

We now turn to the incentives of buyers, sellers, and independent intermediaries to invest in electronic marketplaces. These incentives are important, as developing electronic marketplaces requires substantial investments. The analysis in Section 3 demonstrates that the impacts of these systems on buyers and sellers are substantially different. Consequently, buyers, sellers and independent intermediaries face different incentives to invest in the required technology.

\section{Model 2}

In the setting of model 1 with $n$ buyers and $m$ sellers, assume that investment $x$ in the development of an electronic marketplace will result in search cost $c=c(x)$ for acquiring price and product information. We can assume that $\frac{d c}{d x}<0$ since higher investment should result in lower search costs, and that $\frac{d^{2} c}{d x^{2}}>0$ since there must be diminishing returns to investment as $c$ cannot be negative.

\section{Socially optimal level of investment}

According to the analysis in Section 3.1, at equilibrium each buyer incurs on expectation a search cost of $\frac{1}{2} \sqrt{c(x) t}$ and a utility loss of $\frac{1}{2} \sqrt{c(x) t}$ from imperfect fit of the purchased product offering, for a total inefficiency of $n \sqrt{c(x) t}$. A social planner maximizing the total social surplus would choose investment $x *$ that minimizes $x+n \sqrt{c(x) t}$, solving $\frac{d}{d x}[n \sqrt{c(x) t}+x]=0$. Consequently the optimal social investment $x *$ is obtained by solving $\frac{d c(x)}{d x}=-\frac{2 \sqrt{c(x)}}{n \sqrt{t}}$. For example, if $c(x)=\frac{1}{x^{2}}$, then $x^{*}$ is given by solving $-\frac{2}{x^{3}}=-\frac{2}{n x \sqrt{t}}$, and thus $x^{*}=\sqrt{n} \sqrt[4]{t}$. Under our convexity assumptions, as the number of buyers in the market increases, and as product differentiation increases, the socially optimal level of investment in technology that reduces search costs, such as electronic marketplaces, increases as well.

\section{Seller incentives to invest}

If sellers as a group were to invest in an electronic marketplace that reduces the search cost of their $n$ buyers, they can be expected to capture a certain proportion $\alpha(0 \leq \alpha \leq 1)$ of the 
buyers' efficiency gains ${ }^{16}$. For instance, this could happen by charging buyers a one-time fee for using the system. Airline reservation systems, for example, typically assess a fee for each ticket issued that depends on the number of flight segments but not on the number of searches performed. According to Equation (5), as long as $r \geq 2 \sqrt{c(x) t}$, the sellers realize a profit of $\sqrt{c(x) t}$ from each buyer. Thus the sellers will want to minimize $x+2 \alpha n \sqrt{c(x) t}-n \sqrt{c(x) t}$, i.e., they will choose $x$ to minimize $x+(2 \alpha-1) n \sqrt{c(x) t}$, which they can achieve by solving $\frac{d c(x)}{d x}=-\frac{2 \sqrt{c(x)}}{(2 \alpha-1) n \sqrt{t}}$. It can be seen that sellers will not invest at the socially optimal level unless they can completely capture the buyers' surplus ( $\alpha=1)$. If $\alpha<1$ and our convexity assumptions hold, sellers will underinvest in technology such as electronic marketplaces that reduces search costs. If $\alpha<0.5$, it can be seen that sellers would like to select $x$ such that $\frac{d c(x)}{d x}>0$; since no positive level of investment has this property, this result implies that sellers will not only fail to invest in, but will actually resist the introduction of an electronic marketplace.

Sellers will also face the socially optimal incentives to invest when search costs are so high that they limit the prices that can be charged by the sellers, or cause the market to break down. For instance, if $\sqrt{c t} \geq r>2 \sqrt{c t}$, it was shown in Section 3.2 that sellers can only charge a price $r-\sqrt{c t}$. As a result, sellers' choice of investment in reducing search costs will minimize $x-n r+n \sqrt{c(x) t}$, and thus will satisfy the same condition $\frac{d}{d x}[x+n \sqrt{c(x) t}]=0$ as the socially optimal investment $x^{*}$.

\section{Buyer incentives to invest}

Each buyer benefits from investing in an electronic marketplace by enjoying a lower utility loss of $\frac{1}{2} \sqrt{c(x) t}$ from imperfect matching, a lower search cost of $\frac{1}{2} \sqrt{c(x) t}$, and a lower price of $\sqrt{c(x) t}$. Thus if buyers as a group were to invest in an electronic market reducing their search costs, they would choose their investment to minimize $x-2 n \sqrt{c(x) t}$, i.e., solve $\frac{d c(x)}{d x}=-\frac{\sqrt{c(x)}}{n \sqrt{t}}$. Under our convexity assumptions, buyers would overinvest in electronic

16 If only one or few sellers control the operation of an electronic marketplace, they may be able to hold on to a substantial portion of system benefits $(\alpha>0)$; otherwise competition among sellers is likely to pass system benefits to buyers, driving $\alpha$ to zero. Evidence from the airline reservation systems suggests that if the number of intermediaries is small, these intermediaries are able to reap benefits (albeit small) even after several years of operating their systems (Kleit 1992). 
marketplace technology. This is because in addition to the social gains of this technology, buyers would benefit from rent redistribution at the expense of sellers.

\section{Intermediary incentives to invest}

An intermediary operating an electronic marketplace will be able to charge buyers for access to the system up to their realized savings from reduced search costs and lower prices. ${ }^{17}$ Assuming that the intermediary can capture a fraction $\alpha$ of the benefits generated as a result of its market power and the bargaining structure of the setting, the optimal investment level will minimize $x+2 \alpha n \sqrt{c(x) t}$. Thus, if $\alpha>0.5$ the intermediary will overinvest compared to the socially optimal level; if the benefits are equally split between the intermediary and the buyers ( $\alpha=0.5$ ) then the intermediary's incentives are socially optimal, while if most benefits are competed away ( $\alpha<0.5$ ), the intermediary's incentives to invest are less than their socially optimal level.

\section{Introduction of electronic marketplaces}

In the above setting, sellers are made worse of by electronic marketplaces they introduce if $\alpha<0.5$ and they are always made worse off by electronic marketplaces introduced by buyers or independent intermediaries. As a result, sellers may oppose the introduction of systems that lower buyer search costs. For example, in the summer of 1995, when Andersen Consulting introduced its "Bargainfinder" electronic agent (http://bf.cstar.ac.com/bf) that scouted the Internet sites of music CD stores to find the best seller for a specific CD in terms of price and availability, on-line music retailers resisted the idea (Yovovich 1995). About half of the fourteen initial participating sellers dropped out, and several of the remaining ones eventually took steps to make it more difficult for the Bargainfinder agent software to access their databases and compare prices. This nascent electronic marketplace languished as a result. ${ }^{18}$

This argument may seem at odds with the observation that most real-world electronic marketplaces are initiated by sellers, especially in industries concentrated on the seller side. What the above analysis suggests, however, is that sellers have no incentive as a group to

17 An intermediary may also charge sellers for access to an electronic market that allows new buyers to enter the market. Furthermore, once the system becomes operational, and depending on the intermediary's market power, it may be possible to extract rents from the sellers by threatening to exclude them from the electronic marketplace.

18 If an intermediary is able to capture more than half the benefits generated from its electronic marketplace, the cooperation of sellers can be bought with a transfer payment of one half the generated benefits. In the case of Bargainfinder, the system was introduced as a vehicle to study electronic marketplaces, and did not generate revenues that could make this option feasible. 
introduce an electronic marketplace, because that marketplace will reduce their total profits. On the other hand each seller may want to introduce such a system individually as, if the number of sellers $m$ is large, the revenues that can be generated by charging buyers for the use of an electronic marketplace will exceed the loss of monopolistic rents for that individual seller. ${ }^{19}$ Thus sellers could find themselves in situations resembling the prisoners' dilemma: the first seller to introduce an electronic marketplace would be able to capture most of the generated buyer surplus (achieving a high $\alpha$ ), while if several systems are subsequently introduced, the resulting benefits may be competed away $(\alpha \approx 0)$ together with most seller profits.

If a market is concentrated on the seller side (i.e., $m<<n$ ) and if a substantial part of the generated buyer surplus can be captured by the sellers (high $\alpha$ ), then each of the $m$ sellers may realize more individual benefits from the system than each of the $n$ buyers. Individual sellers may thus have higher incentives to develop an electronic marketplace, even though buyers tend to be the primary beneficiaries of these systems. This is in agreement with evidence from the airline industry, where the electronic marketplace created by airline reservation systems seems to have significantly reduced the airlines' monopoly power over their flying customers, while, initially at least, it generated profits for those airlines that pioneered the introduction of such systems (Hopper 1990). Buyers may also face substantial free rider problems that inhibit their investment in electronic marketplaces: if most of the benefits of these systems are eventually competed away to the advantage of all buyers, then individual buyers may prefer to free-ride on electronic marketplaces introduced by other market participants.

Finally, we saw that in markets where the search costs are high compared to buyer valuations, in monopolistic markets, and in markets where sellers have successfully colluded to avoid price competition, sellers will be able to capture most of the buyer surplus generated by an electronic marketplace. In this type of markets, it is not surprising to see sellers initiate the development of such systems.

Technological developments such as the falling cost of telecommunications and computers, or the ability to implement electronic marketplaces on the Internet, are reducing both the fixed and the variable investments required to implement an electronic marketplace. These developments will precipitate the introduction of such systems in more markets, possibly by lowering the required investment to initiate such a system below the threshold necessary to motivate a buyer or an outside intermediary. These marketplaces, however, cannot succeed

19 It is easy to see that for large enough $m$ and $\alpha, 2 \alpha n \sqrt{c t}>\frac{n \sqrt{c t}}{m}$. 
unless they can attract a sufficient number of sellers; sellers may take advantage of this need to thwart electronic marketplaces controlled by buyers and independent intermediaries before these marketplaces can successfully establish themselves. As mentioned earlier, behavior like this was seen with the Bargainfinder system in the Internet (Yovovich 1995). Formal modeling of these strategic issues is an important area for future research.

\section{Separating search costs for price and product information}

Buyers in a differentiated market face two types of search costs: the cost of obtaining price information and the cost of obtaining information about the product characteristics of a seller offering (i.e., the location of that offering in the product space). In the preceding sections we bundled together these two types of search costs for price and product information, as has been typical in the search cost literature. Although this may be appropriate in some settings (e.g., a buyer may incur a search cost to visit a store and then obtain both price and product information), in other settings it may be possible to separate these two costs. For example, a buyer may be able to telephone a store to obtain a price quote, but then may need to visit the store to obtain reliable product information. In this case, the cost of the visit will be separate (and typically larger) than the cost of the phone call.

The ability to separate the search costs for price and product information is particularly interesting in the context of an electronic marketplace. These systems are unique in their ability to separately influence the search costs for price and product information through appropriate choices in system design. In this section we consider how the equilibrium in model 1 changes if we separate the price and product information components of search costs. Consider a setting with $n$ buyers and $m$ sellers similar to model 1, except that in addition to the "fit" cost, buyers face three types of search costs:

- $\quad c_{1}$ is the search cost to visit a seller $s$-we refer to it as the cost of access to $s$;

- $c_{2}$ is the search cost to acquire price information about the product offered by seller $s$-we refer to it as the cost of price information;

- $c_{3}$ is the cost to acquire information about the product characteristics of the product offered by seller $s$ - we refer to it as the cost of product information.

We assume that a buyer must incur the access cost $c_{1}$ before either the price or the product information can be acquired at their respective costs $c_{2}$ and $c_{3} \cdot{ }^{20}$ If $c_{2}=c_{3}=0$, this setting

20 In this setting, since we assume that buyer priors are not changing (buyers know the distribution of seller prices in advance and they sample with replacement), it would never be sequentially optimal for a buyer to revisit a seller; thus we do not need to address whether the access cost would be paid twice in that case. 
becomes identical to the one analyzed in Section 3.1. Consequently at equilibrium sellers will charge $\sqrt{c_{1} t}$ and buyers will search until they find a seller in their "neighborhood", i.e., at a distance less than $\sqrt{c_{1} / t}$. However, reducing the cost of price information or product information independently has interesting implications of its own.

\subsection{Markets with Low Cost of Price Information}

We first consider a setting corresponding to an electronic marketplace designed to promote price-shopping. Such a marketplace would make it easy to obtain price information, but might still require a higher-cost inquiry (such as a visit) to obtain detailed product information. ${ }^{21}$ At the limit, this marketplace would have $c_{1}=c_{2}=0$ and $c_{3}>0$, creating a market where buyers can learn any seller's price at zero cost, but they must still "visit" that seller to acquire product information.

As in Section 3.1, the unique perfect Bayesian equilibrium is symmetric, with all sellers charging a price $p^{*}$. The condition $S+D t=p^{*}+\sqrt{c t}$ from equation (2) still holds; consequently each seller receives sales from a territory of length $2 \sqrt{c_{3} / t}$, consisting of the interval $\left[-\sqrt{c_{3} / t}, \sqrt{c_{3} / t}\right]$ around that seller's position. Seller $i$ 's total sales are $n / m$, corresponding to the $n / m$ buyers that visit $i$ before they visit some other seller in their neighborhood. At equilibrium, there will be no incentive for seller $i$ to deviate by charging a price of $p^{*}-\delta$, and equation (3) will hold as well, i.e., $Q_{i}\left(p_{i}^{*}, p_{j \neq i}^{*}\right)+p^{*} \frac{d}{d p_{i}}\left[Q_{i}\left(p_{i}, p_{j \neq i}^{*}\right)\right]_{p_{i}=p^{*}}=0$, where $Q_{i}\left(p_{i}, p_{j \neq i}^{*}\right)$ denotes the sales of seller $i$ when the price charged by $i$ is $p_{i}$ while every other seller $j \neq i$ charges price $p^{*}$. As in model 1 , if seller $i$ reduces its price to $p^{*}-\delta$, its territory expands by $2 \delta / t$. However since all other sellers charge price $p^{*}$, and since all prices are known to buyers at zero cost, buyers' optimal strategy is to visit seller $i$ first. The result is that by discounting by $\delta$, seller $i$ will sell to all buyers in its territory, i.e., to $2 n \sqrt{c_{3} / t}+2 n \delta / t$ buyers. Seller $i$ 's incremental sales (and profits) by discounting are $2 n \sqrt{\frac{c_{3}}{t}}\left(p^{*}-\delta\right)+\frac{2 n \delta}{t}\left(p^{*}-\delta\right)-\frac{n}{m} p^{*}$. It can be seen that if the number of sellers is large enough so that $2 n \sqrt{\frac{c_{3}}{t}}>\frac{n}{m}$, i.e., $m>\frac{1}{2} \sqrt{\frac{t}{c_{3}}}$, discounting will be

21 For example, in mid-1996 a buyer looking for a computer monitor can easily acquire a list of prices from a large number of sellers by connecting to the Pricewatch search engine on the Web (www.pricewatch.com), but then will face a larger cost in obtaining additional information for each product offering thus identified. Specifically, the buyer must obtain and evaluate the monitor's specifications, assess the seller's reputation and return policies, and ideally locate a display model at a showroom or at a colleague's office. 
profitable for all $p^{*}>0$, and thus the only equilibrium price is $p^{*}=0$. In other words, making prices freely available to the buyers induced Bertrand-type competition among sellers.

If the cost of product information $c_{3}$ is close to zero, this model is similar to Salop's (1979) setting, where sellers can charge a positive price, which approaches zero asymptotically as the number of sellers $m$ grows large. Contrasting our result to Salop's shows that the cost of product information relative to the cost of price information can significantly affect the resulting equilibrium: when the cost of obtaining product information is the dominant component of search costs, sellers' incentives to discount increase, as they will attract inframarginal as well as marginal buyers.

If the cost of price information $c_{2}$ is small but not zero, there will still be a corresponding $\delta=\delta\left(c_{2}\right)$ that would allow seller $i$ to capture its entire territory by discounting by $\delta$. Since finding $i$ would take the average buyer $m / 2$ tries, we need $\delta>\frac{1}{2} m c_{2}$, and the corresponding equilibrium price will be $p^{*}=\frac{1}{2} m c_{2}$; any price above this would induce sellers to discount.

\subsection{Markets with Low Cost of Product Information}

Now consider a setting corresponding to an electronic marketplace designed to promote competition based on product features. Such a marketplace would make it easy to obtain information about product characteristics, but would require buyers to incur some additional cost to obtain price information. For example, high-quality multimedia product descriptions in standardized formats could help identify product offerings matching the buyer's preferences, while price information could be left out of these descriptions or could be obscured by offering a large number of prices and making it difficult for the buyers to figure out which one applies. Airline reservation systems, for example, make it very easy to identify a convenient flight between a pair of cities, but require substantial effort to identify the lowest applicable fare. At the limit, this marketplace would have $c_{1}=c_{3}=0$ and $c_{2}>0$, creating a market where buyers can compare product features at zero cost, but they face a nonzero cost to acquire price information.

At the unique symmetric perfect bayesian equilibrium with all sellers charging price $p^{*}$, it is now optimal for each buyer is to visit first the seller with the best fitting product offering, as that seller can be costlessly identified, and purchase from that seller. Individual sellers

realize sales of $m / n$ as before, but their territories shrink to an interval $\left[-\frac{1}{2 m}, \frac{1}{2 m}\right]$ around their position, which they completely dominate. At equilibrium there is no searching on price, complete search on product features, and no inefficiency from imperfect matching of buyers and sellers. The unique equilibrium price is the monopoly price since at any lower 
price sellers could increase their price by $\delta$ without any reduction in sales, as long as $\delta<c_{2}$. Sellers will not defect by discounting from the monopoly price, since no additional buyers can be gained.

If sellers charge price $p$, then a buyer at distance $x$ from the closest seller will stay in the market only if $p+x t+c_{2} \leq r$. Each seller will get sales from a territory of length $2 x_{\max }$, where $p+x_{\max } t+c_{2}=r$ (subject to $x_{\max } \leq \frac{1}{2 m}$ ). Thus the length of seller territories will be $2 \frac{r-p-c_{2}}{t}$ and sellers will maximize $2 p \frac{r-p-c_{2}}{t}$, leading to an optimal price $p^{*}=\frac{1}{2}\left(r-c_{2}\right)$. Since $x_{\max } \leq \frac{1}{2 m}$, we also get $\frac{r-p^{*}-c_{2}}{t} \leq \frac{1}{2 m}$, and $p^{*} \geq r-c_{2}-\frac{t}{2 m}$. Thus, if $r-c_{2}-\frac{t}{2 m}>\frac{1}{2}\left(r-c_{2}\right)$, i.e., $m \geq \frac{t}{r-c_{2}}$, sellers set $p^{*}=r-c_{2}-\frac{t}{2 m}$ and no buyers are priced out of the market. Otherwise, sellers set $p^{*}=\frac{1}{2}\left(r-c_{2}\right)$, pricing out buyers further than $\frac{r-c_{2}}{2 t}$ from their nearest seller.

At equilibrium each buyer purchases from the best fitting seller, thus reducing fit costs to their lowest possible level. On the other hand, some buyers may be priced out of the market, creating a deadweight loss. This deadweight loss decreases as the number of sellers increases, or as the search cost $c_{2}$ decreases, and disappears altogether when $m \geq \frac{t}{r-c_{2}}$. In this setting sellers enjoy substantial profits: depending on their number, sellers capture between one half and three quarters of the total surplus generated.

In contrast to the previous case where lower search costs for price information resulted in lower prices and increased competition among sellers, here we see that reducing buyers' cost to obtain information about product features resulted in increased seller monopoly power and profits! To understand why, consider the motivation of buyers to keep searching: their incentive to search reflects the possibility to find a better price and/or a better fitting product offering. If buyers are told in advance which product best fits their preferences, then their incentive to search is reduced. Furthermore, each buyer becomes captive of the seller who offers the best fit, since not purchasing from that seller is certain to increase the buyer's fit cost. As a result the sellers are able to capture much of the surplus generated. 


\subsection{Manipulating Price and Product Information}

We saw that electronic marketplaces that enable price shopping tend to favor buyers and reduce seller monopoly power. How should then sellers react to technological developments that facilitate electronic marketplaces? In the long run it may be impossible to avoid some loss in market power, especially when this power is based on high information costs.

Colluding to prevent an electronic marketplace may induce buyers to introduce such a system themselves, or invite a third-party intermediary into the picture.

Our analysis in this section suggests that the best strategy for sellers may be to control the type of system introduced; a system emphasizing product over price information may allow sellers to maintain high profits while allowing buyers to locate the seller with the best fit. Sellers may be able to charge buyers for this benefit, e.g., through user fees. Moving early to establish this type of system in a market can raise the entry barriers for later entrants, and thus may delay or avoid the introduction of systems less favorable to sellers.

A second tactic, frequently seen in the airline industry, is to compensate for the lower search costs of electronic marketplaces by making it increasingly difficult for the buyers to compare the price of alternative product offerings. For instance, airlines have implemented complicated and ever-changing fare structures, flight restrictions and ticket availability, typically offering several hundred thousand possible fares at any one time, and sometimes hundreds of fares for travel between certain pairs of destinations (Dahl and Miller 1990). This tactic effectively raises buyers' cost of obtaining price information without affecting their cost of obtaining product information. It is interesting that a move by American Airlines to reduce this cost by simplifying the fare structure was resisted by other airlines and was reversed within weeks (Kleit 1992).

A third possibility is to increase the differentiation of product offerings, possibly using the electronic marketplace to help differentiate what would normally be a commodity product. For instance, frequent flyer programs have been successful in achieving this goal in the airline industry, while the Internet offers unprecedented opportunities for the customization of products with a high information or service component.

Buyers have the opposite incentives and would like to encourage an electronic marketplace that facilitates comparisons among sellers' prices and product offerings. If individual buyers lack adequate resources or incentive to introduce a market system, or do not have the clout to induce seller participation, they may form coalitions and introduce jointly owned systems, or form an alliance with a third party organization with the necessary technological sophistication and financial resources. 


\section{Discussion and Conclusions}

\subsection{Implications for Electronic Marketplaces}

The primary function of electronic marketplaces in commodity markets is to provide pricerelated information, while systems in differentiated markets need to provide both price and product information. These systems may allow buyers not only to get easier access to information about seller prices, but also to increase the quality of this information, e.g., by helping buyers to separate transportation costs, financing terms and other means sellers may use to obscure the actual price quoted. In differentiated markets, the system may provide standardized product descriptions and evaluations, which will improve the ability of the buyers to compare different seller offerings.

In commodity markets, decreases in search costs below a certain threshold may destabilize a monopolistic equilibrium and eradicate seller profits. In differentiated markets, seller profits decline smoothly as search costs are reduced. If search costs become low enough, buyers will look at all product offerings and will purchase the one best serving their needs, resulting in a socially optimal allocation. In that case, seller profits depend on the number of product offerings; if that number is very large, seller profits will be close to zero. At the other extreme, very high search costs lead to search and allocation inefficiencies, and eventually cause the market to break down.

Airline reservation systems fit well the model of an electronic marketplace in a differentiated consumer market, and have played an important role in the airline industry. In the 1980s, three systems dominated the market, offered by American (SABRE), United (Apollo), and TWA (PARS). These systems allowed the airlines to lower their operating costs through improved monitoring of their operations and access to better demand data. They were also used as strategic tools, in capacities ranging from bias in their screen displays to the ability to administer a wide gamut of thousands of active fares and promotions. The analysis in Section 3 suggests that electronic marketplaces will increase price competition and reduce seller monopoly power, and will also result in more demanding customers who are less willing to compromise on their preferred product. Airlines apparently experienced both types of effects (Copeland and McKenney 1988, Hopper 1990).

While airline deregulation and increased competition fueled by the reservation systems were adversely affecting the revenues and profits of flight operations for most airlines, the airlines that pioneered reservation systems were enjoying high profits from system-related revenues. In 1980-1982, American Airlines commanded a 40\% gross margin on its SABRE revenues, while flight operations yielded as little as 5\%. TWA made more money in the same period on PARS than from its airline. As a result, airlines with established reservation systems enjoyed 
stock price premiums into the late1980s (Smith 1987), and were deriving some benefits from these systems even in the early 1990s (Kleit 1992).

The current outlook for these systems is less clear, as competition among reservation systems has been increasing. In the long run, air travelers seem to be the only group unambiguously made better off as a result of these systems.

\subsection{Directions for Future Research}

An interesting extension of the above work is the study of the role of heterogeneity in buyers' ability to obtain information about seller offerings, e.g., along the lines of Varian (1980) or Salop and Stiglitz (1982). For example, there may be at least two types of buyers: the ones with access to an electronic marketplace that provides low-cost information about seller prices and product offerings, and the ones without access to such a system, facing higher search costs. Several interesting questions could be studied in this setting, such as the potential externalities created by the users of electronic marketplaces on the buyers that do not have access to such systems, or modeling the benefits buyers outside an electronic marketplace would gain by joining it.

A related problem is the distribution of the payoffs generated by an electronic marketplace among buyers, sellers and intermediaries. Hart and Moore (1990) offer one potential approach to study this issue, using the theory of incomplete contracts and bargaining to study the distribution of property rights and economic benefits among the participants of an economic system. Using a formalization of system benefits along the lines pursued in this article, it should be possible to study the optimal distribution of property rights in electronic marketplaces. Clemons (1990) touches on this issue when he suggests that system topology is linked to the ability of an electronic intermediary to extract monopoly rents; he suggests that intermediation profits are high when the intermediary possesses powerful threat strategies against other system participants. Similarly, Brynjolfsson (1994) and Bakos and Nault (1997) used formal models based on Hart and Moore's theory to study the distribution of property rights and system payoffs.

The models introduced in Sections 5.1 and 5.2 to separate search costs into access costs, the cost of price information and the cost of product information, can be extended to more general settings where one of the components of the search costs is not close to zero, or to settings with multiple dimensions of product differentiation, each with its corresponding search cost. These models could be used to study how the design characteristics of an electronic marketplace affect the welfare of buyers and sellers and the efficiency of the resulting equilibria. Alternatively, the implications of the ability of electronic marketplaces to provide sellers with information about buyers could be explored with a model that includes 
the search costs incurred by sellers to locate appropriate buyers. This extension is particularly interesting in view of the popularity of data mining that enables sellers to obtain information about the preferences of individual buyers, and mass customization, which allows sellers to offer individualized products. Also, rather than assume that search costs are exogenous, they could be explicitly formalized to model the impact of electronic marketplaces beyond a "black box" reduction to the cost of search.

A multiperiod model would capture the repeated nature of transactions in many real-world markets and could address factors such as history, reputation, lock-in, installed base, customer loyalty, and knowledge about customers, all of which are important in electronic marketplaces. Also, several of the arguments in our analysis assume that the number of sellers remains constant; allowing entry and exit would provide an important extension. Finally, it would be interesting to model competition among electronic marketplaces, again allowing for entry and exit. ${ }^{22}$

\subsection{Concluding Remarks}

The main contribution of this article is the study of the economic impacts of electronic marketplaces by focusing on one of their most salient features, the reduction in buyer search costs. The impact of electronic marketplaces was analyzed by developing models that combine search costs and a differentiated market with heterogeneous buyer tastes and seller product offerings. Reduced search costs were shown to have a significant impact on market equilibria, resulting in increased allocational efficiency and possibly lower prices and increased competition among sellers. These theoretical results have several implications for the functionality and the strategic potential of electronic marketplaces.

The ability of electronic marketplaces to increase market efficiency aggregated over the entire economy, makes the provision of electronic intermediation services an important market with potentially large rewards. As the infrastructure for high-speed digital telecommunications becomes widely available to businesses and consumers, including the Internet and other standardized tools to access information, the economics of providing electronic intermediation services are being transformed. The investments in startup hardware, development costs, and continuing maintenance required to implement an electronic marketplace are likely to be reduced, helping electronic commerce take hold and leading to substantial increases in economic efficiency.

22 I thank three anonymous reviewers and the Associate Editor for suggesting several of these extensions. 


\section{References}

Bakos, J. Y. "Interorganizational Information Systems: Strategic Opportunities for Competition and Cooperation." Ph. D. Dissertation, MIT Sloan School of Management, November 1987.

Bakos, J. Y. "A Strategic Analysis of Electronic Marketplaces." MIS Quarterly, September 1991, pp. 295-310

Bakos, J. Y. and Nault, B. R. "Ownership and Investment in Electronic Networks."

Information Systems Research, vol. 8, number 4, December, 1997.

Brynjolfsson, E. "Information Assets, Technology and Organization." Management Science, Volume 40, Number 12, December 1994, pp. 1645-1662.

Chamberlin, E. H. The Theory of Monopolistic Competition. Harvard University Press, Cambridge, Ma., 1933.

Clemons, E. K. "MAC -- Philadelphia National Bank's Strategic Venture in Shared ATM Networks." Journal of MIS, Vol. 6, No. 5, Summer 1990.

Clemons, E. K. "Evaluation of Strategic Investments in Information Technology." Communications of the ACM, January 1991.

Copeland, D. G. and McKenney, J. L. "Airline Reservation Systems: Lessons from History." MIS Quarterly, June 1988.

Dahl, J. and Miller, M. W. "Airlines Concede Ticketing Chaos Could Recur." Wall Street Journal, September 3, 1990, p. B1.

Diamond, P. A. "Search Theory." Manuscript prepared for the New Pelgrave. August 1985.

Economist. "No computers for Euro-bonds." 30 May 1987, p.14.

Hart, O. and Moore, J. "Property Rights and the Nature of the Firm." Journal of Political Economy, vol. 98, number 6 (1990), pp. 1119-1158.

Harvard Business School Case \#9-189-088. "American Gem Market System." HBS Case Services, Boston, Ma., 1988.

Harvard Business School Case \#9-190-001. "AucNet: TV Auction Network System." HBS Case Services, Boston, Ma., 1989.

Hopper, M.D. "Rattling SABRE-New Ways to Compete on Information." Harvard Business Review, May-June 1990, pp. 118-125. 
Hotelling, H. "Stability in competition." Economic Journal, 39 (1929), pp. 41-57.

Kleit, A. N. "Computer Reservation Systems: Competition Misunderstood." Antitrust Bulletin, Volume 37, Number 4, December 1992, pp. 833.

Malone, T. W., Benjamin, R. I. and Yates, J. "Electronic Markets and Electronic Hierarchies: Effects of Information Technology on Market Structure and Corporate Strategies." Communications of the ACM, Volume 30, Number 6, June 1987.

Malone, T. W. and Crowston, K. "The Interdisciplinary Study of Coordination." $A C M$ Computing Surveys, Volume 26, Number 1, March1994, pp. 87-119.

Markels, A. "Job Hunting Takes Off in Cyberspace." Wall Street Journal, September 20, 1996, p. B1.

Perloff, J. M. and Salop, S. C. "Equilibrium with Product Differentiation." Review of Economic Studies, 52, 1985, pp. 107-120.

Salop, S.. "Monopolistic competition with outside goods." Bell Journal of Economics, 10, 1979, pp. 141-156.

Salop, S. and Stiglitz, J. E. "The Theory of Sales: A Simple Model of Equilibrium Price Dispersion with Identical Agents." American Economic Review, Vol. 72, December 1982, pp. 1121-1130.

Schmalensee, R. "Entry Deterrence in the Ready-to-Eat Breakfast Cereal Industry." Bell Journal of Economics, 9, 1978, pp. 305-327.

Smith, R. "AMR's Outlook is Clouded as Competition Erodes Profit of Airline Unit's Sabre System." Wall Street Journal, May 28, 1987, p. 65.

Stiglitz, J. E. "Imperfect Information in the Product Market." In Handbook of Industrial Organization, R. Schmalensee and R. D. Willig (editors), North-Holland, New York 1989, pp. 769-847.

Yovovich, B. G. "Smart Agents Do the Shopping; Sophisticated Tools Wending the Web in Search of Bargains." Advertising Age, July 31, 1995, p. 8.

Varian, H. "A model of Sales." American Economic Review, vol. 70, September 1980, pp. 651-659. 